Article

\title{
Evaluation of a Two-Tier Screening Pathway for Congenital Adrenal Hyperplasia in the New South Wales Newborn Screening Programme
}

\author{
Fei Lai ${ }^{1,2, *}$, Shubha Srinivasan ${ }^{2,3}$ and Veronica Wiley ${ }^{1,2}$ \\ 1 Department of NSW Newborn Screening Programme, The Sydney Children Hospital Network, Westmead, \\ NSW 2145, Australia; veronica.wiley@health.nsw.gov.au \\ 2 Faculty of Medicine and Health, The University of Sydney Children's Hospital Westmead Clinical School, \\ Westmead, NSW 2145, Australia; shubha.srinivasan@health.nsw.gov.au \\ 3 Department of Endocrinology, The Sydney Children's Hospital Network, Westmead, NSW 2145, Australia \\ * Correspondence: fei.lai@health.nsw.gov.au
}

Received: 30 June 2020; Accepted: 7 August 2020; Published: 12 August 2020

\begin{abstract}
In Australia, all newborns born in New South Wales (NSW) and the Australia Capital Territory (ACT) have been offered screening for rare congenital conditions through the NSW Newborn Screening Programme since 1964. Following the development of the Australian Newborn Bloodspot Screening National Policy Framework, screening for congenital adrenal hyperplasia (CAH) was included in May 2018. As part of the assessment for addition of $\mathrm{CAH}$, the national working group recommended a two-tier screening protocol determining $17 \alpha$-hydroxyprogesterone (17OHP) concentration by immunoassay followed by steroid profile. A total of 202,960 newborns were screened from the 1 May 2018 to the 30 April 2020. A threshold level of 17OHP from first tier immunoassay over $22 \mathrm{nmol} / \mathrm{L}$ and/or top $2 \%$ of the daily assay was further tested using liquid chromatography tandem mass spectrometry (LC-MS/MS) steroid profiling for 17OHP (MS17OHP), androstenedione (A4) and cortisol. Samples with a ratio of (MS17OHP + A4)/cortisol $>2$ and MS17OHP $>200 \mathrm{nmol} / \mathrm{L}$ were considered as presumptive positive. These newborns were referred for clinical review with a request for diagnostic testing and a confirmatory repeat dried blood spot (DBS). There were 10 newborns diagnosed with $\mathrm{CAH}$, (9 newborns with salt wasting $\mathrm{CAH}$ ). So far, no known false negatives have been notified, and the protocol has a sensitivity of $100 \%$, specificity of $99.9 \%$ and a positive predictive value of $71.4 \%$. All confirmed cases commenced treatment by day 11 , with none reported as having an adrenal crisis by the start of treatment.
\end{abstract}

Keywords: congenital adrenal hyperplasia; newborn screening; 17- $\alpha$ hydroxyprogesterone; immunoassay; liquid chromatography tandem mass spectrometry; screening pathway

\section{Introduction}

Congenital adrenal hyperplasia $(\mathrm{CAH})$ is an autosomal recessive disorder that occurs when there is a disruption in any of the enzymes along the adrenal steroidogenesis pathway [1-3]. CAH is categorised depending on which enzyme is affected. The severity of symptoms is inversely correlated with nonfunctioning enzyme activity [4]. The most common enzyme defect is 21-hydroxylase deficiency accounting for over $95 \%$ of cases. This form of $\mathrm{CAH}$ is subtyped into classical CAH and non-classical CAH. Classical CAH is further divided into salt-wasting CAH (SWCAH) and simple-virilising CAH (SVCAH) [4-6]. SWCAH, accounting for approximately $75 \%$ of classical CAH presentation, is the most severe form of $\mathrm{CAH}[7,8]$. The incidence worldwide of classical CAH is usually considered to be approximately 1:14,000 to 1:18,000; however, it varies depending on the ethnic background [2]. Reported observed incidence is highest in Yupik Eskimos from Southern Alaska at 1:282 [9]. 
Newborn screening for $\mathrm{CAH}$ began with the development of a radioimmunoassay by Pang et al., 1977 [10] measuring $17 \alpha$-hydroxyprogesterone(17OHP) using blood on microfilter paper. Since then, worldwide CAH screening or pilot studies have ensued [11-22]. Newborn screening for $\mathrm{CAH}$ is aimed at identifying newborns with SWCAH promptly to prevent a life threatening adrenal crisis, thus reducing morbidity and mortality in affected individuals [23]. Detrimental adrenal and salt wasting crises occur within the first 2 to 3 weeks of life in newborns with SWCAH. Early clinical symptoms can be non-specific such as poor feeding, vomiting, diarrhoea and sepsis, which can lead to erroneous diagnoses [24]. Population newborn screening provides the opportunity to detect and treat those with CAH before the onset of significant symptoms.

Newborn bloodspot screening in Australia has been established since the late 1960s [25-27]. There are five state government-funded programs, which are located in Adelaide, Brisbane, Melbourne, Perth, and Sydney [28]. However, until recently New Zealand was the only center in Australasia screening for CAH [28]. In Australia, in New South Wales (NSW) and the Australia Capital Territory (ACT), a two-year pilot study was performed from 1st October 1995 to 30th September 1997, assessing the benefits and feasibility of screening $\mathrm{CAH}$ in newborns using an immunoassay for 17OHP with different follow-up action depending on birthweight and concentration of 17OHP compared to clinical diagnoses for newborns born in other states of Australia. Based on the findings from this study, implementing screening for $\mathrm{CAH}$ was considered justified [29]. However, funding for screening for $\mathrm{CAH}$ was not approved by the state governments. The decision was based on the concern of the harm caused by the number of false positive cases in the screened population as well as the evidence that the diagnosis for unsuspected cases in the screened population (median age: 13 days) was not significantly less than for the unscreened population (median age: 16 days).

In Australia, the inclusion of newborn screening for $\mathrm{CAH}$ was proposed to each state government at various times over the intervening years by the Australasian Pediatric Endocrine Group and the Human Genetic Society of Australasia (HGSA) [30]. A request was forwarded to the federal health minister in 2013. However, the process of adding CAH screening was challenging, as there was an absence of clear national policies or guidelines endorsed by all governments to support uniform newborn bloodspot screening. CAH was included as a recommended disorder in Australia in May 2018 due to the efforts of a time-limited multi-disciplinary CAH Assessment Working Group (CAHWG). The CAHWG also trialed the "Newborn Screening Bloodspot National Policy Framework", which included the tools for assessment of the inclusion or removal of recommended conditions [25].

The NSW Newborn Screening Programme commenced screening for CAH in May 2018 using the proposed recommended two-tier method protocol. This included all dried blood spot (DBS) samples being initially measured for $17-\alpha$ hydroxyprogesterone (17OHP) using immunoassay followed by a second tier of steroid profiling using liquid chromatography tandem mass spectrometry (LC-MS/MS) for a percentage of samples with the highest 17OHP level. Whilst the CAHWG noted that the percentage could have differed in each state program, it was estimated to have been between 1 and $2 \%$ of sample results. This paper provides an evaluation of the first 2 years of implementation of screening for CAH in NSW.

\section{Materials and Methods}

\subsection{Samples}

All parents are provided with a multimedia information on newborn screening, including a pamphlet (Newborn Bloodspot Screening-Tests to Protect Your Baby) by the maternity health provider. Furthermore, educational videos and specific fact sheets are available on the website for parents and health professionals (https://www.schn.health.nsw.gov.au/find-a-service/laboratory-services/unhbox। voidb@x (hbox\{newborn-screening\}).

Newborn screening is not mandatory in Australia, and therefore following parent(s) consent, a heel prick blood spot sample is collected onto special pre-printed filter card provided by NSW 
Newborn Screening Programme, ideally when the baby is 48 to $72 \mathrm{~h}$ after birth. The sample is air dried before being sent to the laboratory via a courier or local Australia Post. All DBS samples received in the laboratory by 10:15 am each day are processed as a batch on that working day.

Once received in the laboratory, the integrity and validity of each sample is determined. A repeat DBS sample is requested for samples that are deemed unsuitable due to being contaminated, insufficient or collected less than $24 \mathrm{~h}$ after birth, or having been collected after blood products were given to the newborn. A repeat sample is also requested at 1 month of age for any low birth weight $(<1.5 \mathrm{~kg})$ or premature ( $<30$ weeks gestation) newborn. DBS samples with relevant clinical or family history information are processed for all routine screening tests plus assessed for further testing inclusion. Each initial DBS sample is allocated a unique laboratory sample identification number and with its corresponding demographic information entered into the laboratory information system (LabMaster Database) where a unique patient identification number is generated. Repeat samples received are matched with the previously generated unique patient identification number.

The DBS samples are then punched into 96 well microtiter plates using Panthera-Puncher ${ }^{\mathrm{TM}}$ 9 (Perkin Elmer, Turku, Finland) to simultaneously punch and distribute $3.2 \mathrm{~mm}$ blood disc into 6 different microtiter plates, one of which is a plate for immunoassay of $17 \alpha \mathrm{OHP}$.

\subsection{Immunoassay}

The concentration of 17OHP is initially determined on all DBS samples received using GSP ${ }^{\circledR}$ Neonatal $17 \alpha$-OH-Progesterone assay kit (PerkinElmer, Turku, Finland) on the 2021-0010 Genetic Screening Platform ${ }^{\circledR}$ (PerkinElmer, Turku, Finland) (GSP). The GSP assay is a competitive dissociation-enhanced lanthanide fluorescent immunoassay (DELFIA) (PerkinElmer, Turku, Finland). The kit provides the antibody-coated microtiter plates, calibrators, quality controls and all the reagents required to perform the immunoassay. A set of external quality control samples is also included in each daily assay. In our laboratory, the validation study for this kit using 5000 deidentified routine samples from full-term, normal birthweight infants established the 98th centile for $17 \mathrm{OHP}$ was $21.8 \mathrm{nmol} / \mathrm{L}$ whole blood. Therefore, samples with $17 \mathrm{OHP} \geq 22 \mathrm{nmol} / \mathrm{L}$ and/or falling in the top $2 \%$ of all samples received for the daily assay for any birthweight were further tested using the second-tier LC-MS/MS steroid panel analysis. Samples with any clinical information or family history relevant to CAH were also tested using the LC-MS/MS steroid panel analysis.

\section{3. $L C-M S / M S$}

Unlabeled 17OHP, hydrocortisone and 4-Androstene-3,17-dione (A4) were obtained from LGC Dr. Ehrenstorfer GmbH (Augsburg, Germany). The isotopically labeled internal standard D8-17-OHP, [17-Hydroxyprogesterone(2,2,4,6,6,21,21,21-D8, 98\%)], D7-Androstenedione, [4-Androstene-3,17-dione (2,2,4,6,6,16,16-D7, 97\%)] and D4-Cortisol [Cortisol (9,11,12,123-D4, 98\%)] (Cambridge Isotope Laboratories, Inc, Andover, MA, USA). Deep well microtiter plates (1000 $\mu \mathrm{L})$ were supplied from LVL Technologies (Crailsheim, Germany), and microplate 96 plate pp flat bottom were supplied from Greiner Bio-One International (Frickenhausen, Germany). Fisher Chemical ${ }^{\mathrm{TM}}$ Optima ${ }^{\mathrm{TM}}$ LC-MS solvent from Thermo Fisher Scientific Australia Pty Ltd. (Victoria, Australia) and formic acid were obtained from Ajax Univar, Thermo Fisher Scientific (Victoria, Australia). Ammonium acetate suitable for mass spectrometry was supplied from Sigma Aldrich (WGK, Darmstadt, Germany).

The LC-MS/MS steroid assay for quantitation of 17OHP (MS17OHP), A4 and cortisol was a modified version of the assay from Rossi et al. [31]. The modifications were that stock for 17OHP, A4 and cortisol, and were made by dissolving unlabeled solid steroid compound in methanol:isopropanol (80:20 v/v) instead of ethanol; $75 \mu \mathrm{L}$ of each calibrator was spotted onto filter cards rather than $25 \mu \mathrm{L}$; only one $3.2 \mathrm{~mm}$ blood disc was punched from each calibrator, control and sample and eluted with $220 \mu \mathrm{L}$ of methanol:water (95:5 $v / v)$ containing internal standards (deuterated 17OHP, A4 and cortisol) in a deep well polypropylene plate $(1000 \mu \mathrm{L})$. The eluate was transferred to a 96 well flat bottom polypropylene plate and dried using warm air $\left(40^{\circ} \mathrm{C}\right)$ and reconstituted with $200 \mu \mathrm{L}$ of methanol:water 
(50:50 v/v) containing $2 \mathrm{nM}$ ammonium acetate and 0.1\% formic acid. Samples were analysed using ACQUITY XEVO ${ }^{\circledR}$ TQ-S (Waters, Milford, MA, USA). The ACQUITY XEVO TQS Targetlynx ${ }^{\mathrm{TM}}$ software (version 4.1, Waters, Milford, MA, USA) was used to calculate each steroid concentration. Results of steroid quantitation for a daily batch were available within $2 \mathrm{~h}$. In our laboratory, the assay has proven to be robust and reproducible with a linear calibration curve $\left(r^{2}=0.99\right)$ for all three steroid analytes and coefficient variation of $<10 \%$ for each of the three steroid analytes.

\subsection{Criteria for and Follow-Up of an Abnormal Screen}

A combination of the MS17OHP concentration and the ratio (17OHP + A4)/cortisol) was used to determine whether diagnostic testing was required. Newborns with a MS17OHP level $>200 \mathrm{nmol} / \mathrm{L}$ or $>25 \mathrm{nmol} / \mathrm{L}$ with a ratio of $>2$ were considered screen positive for $\mathrm{CAH}$ and referred for diagnostic testing. The pediatrician or general practitioner named on the DBS card was contacted to organize urgent further samples, including a repeat DBS sample and plasma, to quantitate electrolytes, glucose and a full steroid profile and to perform a clinical review of the baby. Figure 1 shows the analytical protocol. Results obtained by the screening laboratory were reviewed together with the diagnostic results and clinical evaluation to determine the diagnosis.

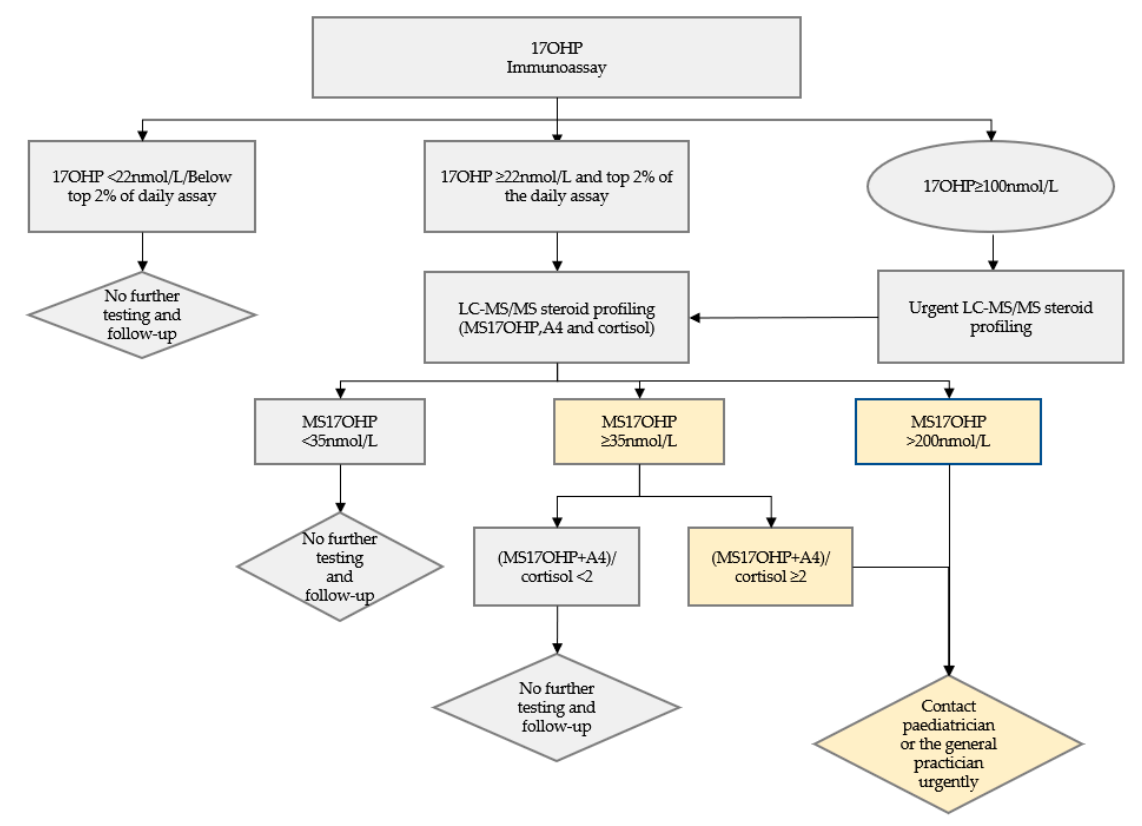

Figure 1. Analytical two-tier congenital adrenal hyperplasia (CAH) screening protocol using immunoassay as first tier followed by steroid profiling using liquid chromatography tandem mass spectrometry (LC-MS/MS) as a second-tier testing.

\section{Results}

There were 202,960 newborns tested during the period of May 2018 to April 2020, including 102,865 males. Of those screened, 2308 were from infants with very low birth weight $(<1.5 \mathrm{~kg})$. There were 206,469 samples, including the repeat dried blood spot collection (e.g., for screen positive, initial sample unsuitable or due to very low birthweight) analysed for 17OHP level using immunoassay. All samples were analysed for $17 \mathrm{OHP}$ level before day 8 of age with the exception of $0.02 \%$ of newborns with low birth weight and $0.22 \%$ of newborns with normal birth weight. Second-tier LC-MS/MS steroid profiling was required for 4218 samples after selecting the top $2 \%$ threshold of the daily immunoassay and any screen positive samples arising from the immunoassay. Of the total number from these samples, 927 (40.2\%) newborns with very low birth weight and 2441 (1.2\%) newborns with normal birthweight had a $17 \mathrm{OHP}$ level above $22 \mathrm{nmol} / \mathrm{L}$. 
Data collected showed that the 17OHP concentration from both immunoassay and LC-MS/MS obtained from newborns with very a low birth weight tended to be higher than that of the newborns with normal birth weight. Refer to Figure 2 .
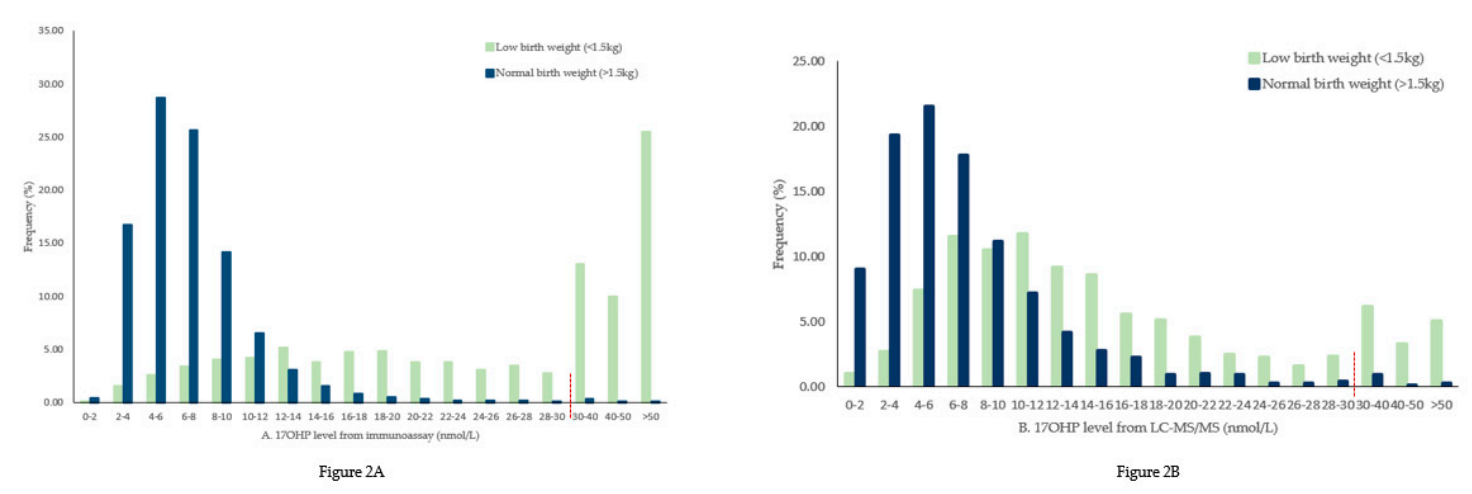

Figure 2. Distribution frequency of $17 \alpha$-hydroxyprogesterone (17OHP) level. (A). 17OHP level (nmol/L) from immunoassay and (B). 17OHP level from LC-MS/MS.

The number of presumptive positive samples based solely on MS17OHP $>25 \mathrm{nmol} / \mathrm{L}$ was 241; however, after applying the ratio calculation of (MS17OHP + A4)/cortisol or for samples with MS17OHP $>200 \mathrm{nmol} / \mathrm{L}$, there were 14 newborns who were deemed presumptive positive. Following diagnostic sample results and clinical review, 10 were proven to have CAH with 9 SWCAH and 1 newborn classified SVCAH. There was a higher proportion of males in the newborns (6/10) diagnosed with CAH.

Samples with clinical information supplied such as ambiguous genitalia, indeterminate sex and query $\mathrm{CAH}$ were also tested with LC-MS/MS steroid profiling regardless of the immunoassay $17 \mathrm{OHP}$ level. A total of 20 newborns had clinical information suggestive of CAH. Out of the 20 newborns, 17 newborns had an initial immunoassay result for $17 \mathrm{OHP}$ of less than $13 \mathrm{nmol} / \mathrm{L}$ and normal MS17OHP level. The other 3 newborns (case numbers 1, 5 and 7 in Tables 1 and 2) were confirmed to have CAH. All confirmed cases were initially notified by day 9 of life, and all had treatment commenced by day 20 . 
Table 1. Cases of CAH follow-up due to presumptive positive for New South Wales (NSW) Newborn Screening Programme from 1 May 2018 to 31 December 2019.

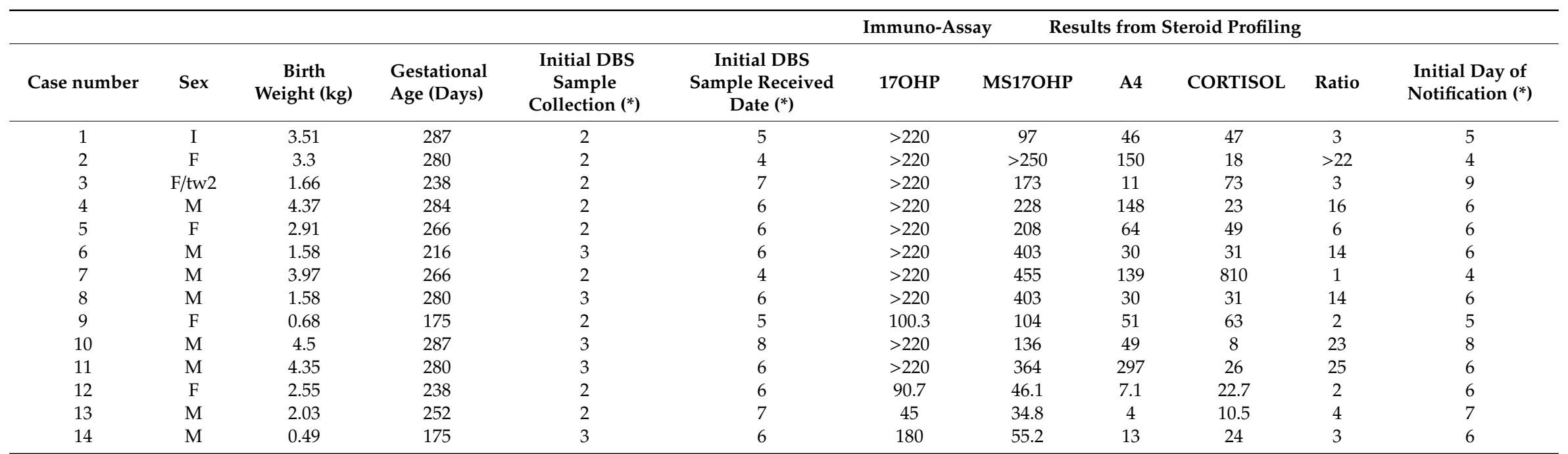

Analytes are displayed in nmol/L whole blood; NFT-no further follow-up; $\left(^{*}\right)$ all samples collection and received date are calculated from date of birth, case number 3 is a female and twin number 2. 
Table 2. Diagnostic results.

\begin{tabular}{|c|c|c|c|c|c|c|c|c|c|c|c|c|}
\hline Case Number & $\mathrm{Na}^{*}$ & $\mathrm{~K}^{*}$ & Glucose * & $17 \mathrm{OHP} * *$ & $\mathrm{~A} 4{ }^{* *}$ & CORTISOL ${ }^{* *}$ & TESTOSTERONE ** & Family History & Symptoms & $\begin{array}{c}\text { Diagnosis } \\
\text { Suspected before } \\
\text { Notification }\end{array}$ & $\begin{array}{c}\text { Final } \\
\text { Diagnosis }\end{array}$ & $\begin{array}{c}\text { Treatment } \\
\text { Commencement } \\
\text { Day }(*)\end{array}$ \\
\hline 1 & 141 & 4.9 & & 234 & & 320 & 5.8 & $\mathrm{~N}$ & virilisation & $\mathrm{Y}$ & SW CAH & 5 \\
\hline 2 & 119 & 7.3 & 3.8 & 680 & 130 & 61 & & $\mathrm{~N}$ & poor weight gain & $\mathrm{N}$ & SW CAH & 11 \\
\hline 3 & 130 & 6.1 & 30.3 & & & & & $\mathrm{~N}$ & & $\mathrm{~N}$ & SW CAH & 9 \\
\hline 4 & 136 & 5.8 & 4.2 & 212 & $>40$ & 86 & 26.7 & $\mathrm{~N}$ & & $\mathrm{~N}$ & SW CAH & 7 \\
\hline 5 & 132 & 8 & 4.6 & 175 & 25 & 87 & 2.2 & $\mathrm{~N}$ & $\begin{array}{l}\text { hypotension (associated } \\
\text { with acute respiratory } \\
\text { illness) virilisation }\end{array}$ & $\mathrm{Y}$ & SW CAH & 7 \\
\hline 6 & 133 & 5.7 & 3.8 & $>460$ & $>37$ & 104 & 51.4 & $\mathrm{~N}$ & poor feeding, preterm & $\mathrm{N}$ & SW CAH & 8 \\
\hline 7 & 136 & 5.3 & & 652 & & 88 & & $\mathrm{Y}$ & $\begin{array}{l}\text { mild scrotal-transient, } \\
\text { excess pigmentation }\end{array}$ & $\mathrm{Y}$ & SV CAH & 2 \\
\hline 8 & 133 & 5.7 & 3.8 & $>460$ & $>37$ & 104 & 51 & $\mathrm{~N}$ & poor feeding, preterm & $\mathrm{N}$ & SW CAH & 8 \\
\hline 9 & & & & & & & & & & & NFT & \\
\hline 10 & 135 & 5.5 & 5 & 340 & $>38$ & 31 & 3.5 & $\mathrm{~N}$ & & $\mathrm{~N}$ & SW CAH & 10 \\
\hline 11 & 132 & 7 & & 498 & & 64 & & $\mathrm{~N}$ & lethargy & $\mathrm{N}$ & SW CAH & 20 \\
\hline 12 & 135 & 5.6 & 6.5 & 13 & & 258 & & & & & NFT & \\
\hline 13 & & & & & & & & & & & NFT & \\
\hline 14 & & & & & & & & & & & NFT & \\
\hline
\end{tabular}

${ }^{*}$ Analytes are displayed in $\mathrm{mmol} / \mathrm{L} ; * *$ analytes are displayed in nmol/L; case numbers 9,13 and 14 only had a repeat dried blood spot recollection, and were clinically reviewed but had no plasma sample recollection; NFT-no further testing or follow-up; $\left(^{*}\right)$ days calculated from date of birth. 


\section{Discussion}

Despite inclusion of screening for CAH in many newborn screening programs internationally, it has not been included in all developed programs. There remain reservations, as CAH can be detected through clinical assessment and there are noted to be high false-positive rates generated from immunoassay in low birth weight premature infants [22,32,33]. A study from the United Kingdom argued that screening for $\mathrm{CAH}$ has no impact on the morbidity and mortality of patients with $\mathrm{CAH}$ and therefore does not include CAH in its screening program [34]. It has also been suggested that newborn screening for CAH only benefits male newborns, as females can be clinically detected due to virilisation [35]. However, countries around the world screening for CAH have demonstrated that the benefits from early detection of newborns with CAH include reducing morbidity and mortality, especially for newborns with SWCAH, and can assist in gender assignment for newborn with SVCAH [36].

There have been several strategies implemented by screening programs to improve the specificity of CAH screening. Improvement in the specificity was observed when the cut-off level of $17 \mathrm{OHP}$ was stratified based on either gestational age or birth weight and/or age of sampling [1,14,16,18,37-40]. Although gestational age stratification of $17 \mathrm{OHP}$ concentration was shown to give higher specificity, birth weight stratification has been more widely used [22,41,42]. However, even with the implementation of these strategies, $1 \%$ of newborn may require recollection [40]. Similarly, in NSW a two-year pilot program from 1st October 1995 to 30th September 1997 [29] showed that despite stratified action limits for low birth weight newborns there were $6 \%$ of infants $<2 \mathrm{~kg}$ birth weight requiring further sample collection compared to $0.3 \%$ of infants with birth weight $>2 \mathrm{~kg}$. In an effort to simplify the potential use of multiple action limits and assess the expected total workload for each state program, the CAHWG recommended the use of a percentile cut-off for referral to second tier without stratification due to birth weight or gestational age [43]. By performing a second-tier assay on the top $2 \%$ of the daily samples received, our laboratory screening of $\sim 100,000$ newborns per year was an average required to test 8 samples by steroid profile each day, which could have been reduced to 5 to 6 depending on the stratified action limits. The time difference and cost for processing 8 versus 5 samples was deemed insignificant.

The use of a second-tier LC-MS/MS steroid profile was first presented by Lacey et al. measuring 17OHP, A4 and cortisol [24]. By incorporating a second tier of steroid profiling using LC-MS/MS and the use of (MS17OHP + A4)/cortisol) ratio, the NSW Newborn Screening Programme has successfully screened over 200,000 newborns for CAH. In order to simplify the test cascade algorithm, it was determined that $2 \%$ of the daily population of samples would be tested with the second-tier assay. During initial evaluation of the 17OHP immunoassay on 5000 samples, the 98th centile of those with a birth weight $>1.5 \mathrm{~kg}$ was $22 \mathrm{nmol} / \mathrm{L}$ whole blood. Therefore, to ensure all samples received that would be in the top $2 \%$ of a year, all samples with $17 \mathrm{OHP}>22 \mathrm{nmol} / \mathrm{L}$ were further tested. Using this protocol 14 newborns required further samples. There were 10 newborns diagnosed with $\mathrm{CAH}$ after diagnostic testing and a full clinical review: 1 SVCAH; 9 SWCAH (5 males, 3 females and 1 indetermine sex (chromosomally female)). All 9 infants with SWCAH had no prior family history of CAH, although 3 (cases 1, 5 and 7) of the newborns did have clinical observations noted on the DBS sample (Tables 1 and 2). The newborn with SVCAH (case 7) had a family history of CAH. Although this newborn had a steroid ratio of 1, the MS17OHP level was grossly elevated, prompting further follow-up action.

The four presumptive positive newborns requiring additional follow-up due to abnormal ratio were all deemed to be normal after either a DBS sample recollection, clinical review or diagnostic testing, and all remain well. Two of the newborns were extremely premature (Table 1). The protocol used therefore only provided a few false positives $(4 / 202,960)$ and had no known false-negative results. We also successfully notified likely CAH cases before any of the newborns presented with an adrenal crisis. 
There have been various studies investigating the feasibility of increasing the number of analytes in the steroid panel to increase specificity and sensitivity [44-48]. There are studies that show that the inclusion of 21-deoxycortisol and 11-deoxycortisol is more specific for detecting SWCAH by excluding $\beta$-hydroxylase deficiency [47-50]. Investigation of additional ratios (i.e., $17 \mathrm{OHP}+21$-deoxycortisol/cortisol) has been shown to be specific for 21 hydroxylase deficiency [49]. Further studies will be carried out to determine if the addition of 21-deoxycortisol and 11-deoxycortisol will be beneficial to our screening program.

SWCAH can present with a life-threatening adrenal crisis within the first two weeks of life [51]. Screening for $\mathrm{CAH}$, notification of suspicion and diagnosis needs to be achieved before a potential adrenal crisis occurs. Using the two-tiered protocol, all suspected cases of CAH were notified by day 9 of life.

The gene that encodes the 21-hydroxylase enzyme is CYP21A2. Molecular analysis of CYP21A2 variant is hampered by the difficulty of isolating the highly homologous pseudogene CYP21A1P from the active CYP21A2 gene. Further, current molecular assays require at least 2 days to provide results, therefore the length of time to generate results is a deterrent for newborn screening [36,52]. However, variant analysis of the CYP21A2 gene has the potential for further increasing the specificity and sensitivity for screening CAH by basing it on genotype/phenotype studies. Biochemical analysis interferences, such as prematurity or stress of newborns and assay steroid cross reactivity, do not affect molecular variant analysis [53]. Variant analysis has been reported to be able to further discriminate SVCAH from SWCAH [53]; however, so far the literature suggests that variant analysis has only been used as an adjunct for screening [36]. This may change in the near future as technologies advance, for example, using next-generation sequencing for the CYP21A2 gene was reported to be cost effective and less time consuming [54]. Therefore, the emergence of targeted next-generation sequencing should be explored as a feasible screening option.

In conclusion, by following the recommended screening pathway from the national newborn bloodspot policy, the NSW Newborn Screening Programme has successfully screened over 200,000 newborns for CAH detecting an incidence of SWCAH of 1:22,551. We achieved a 100\% sensitivity and a specificity of $99.9 \%$, and the positive predictive value was $71.4 \%$. All newborns screened with positive SWCAH were notified before any adrenal crisis occurred, thereby reducing the need for intensive care intervention.

Author Contributions: Conceptualization, V.W.; methodology, V.W.; writing-original draft preparation, F.L.; writing-review and editing, V.W. and S.S.; All authors have read and agreed to the published version of the manuscript.

Funding: This research received no external funding.

Acknowledgments: The author would like to acknowledge everyone in the department of NSW Newborn Screening Programme for their contributions.

Conflicts of Interest: The authors declare no conflict of interest.

\section{References}

1. Speiser, P.W.; Arlt, W.; Auchus, R.J.; Baskin, L.S.; Conway, G.S.; Merke, D.P.; Meyer-Bahlburg, H.F.L.; Miller, W.L.; Murad, M.H.; Oberfield, S.E.; et al. Congenital adrenal hyperplasia due to steroid 21-hydroxylase deficiency: An endocrine society clinical practice guideline. J. Clin. Endocrinol. Metab. 2018, 103, 4043-4088. [CrossRef] [PubMed]

2. Witchel, S.F.; Azziz, R. Congenital adrenal hyperplasia. J. Pediatric Adolesc. Gynecol. 2011, 24, 116-126. [CrossRef] [PubMed]

3. Hannah-Shmouni, F.; Chen, W.; Merke, D.P. Genetics of congenital adrenal hyperplasia. Endocrinol. Metab. Clin. N. Am. 2017, 46, 435-458. [CrossRef] [PubMed]

4. Simpson, H.; Hughes, I. Congenital adrenal hyperplasia. Medicine 2017, 45, 502-505. [CrossRef]

5. Speiser, P.W.; White, P.C. Congenital adrenal hyperplasia. N. Engl. J. Med. 2003, 349, 776-788. [CrossRef] 
6. Wass, J.A.H.; Stewart, P.M. Oxford Textbook of Endocrinology and Diabetes; Oxford University Press: Oxford, UK, 2011.

7. Nimkarn, S.G.P.; Yau, M.; New, M.I. 21-Hydroxylase Deficiency Congenital Adrenal Hyperplasia; University of Washington: Seattle, WA, USA, 2016.

8. Nimkarn, S.; Lin-Su, K.; New, M.I. Steroid 21 hydroxylase deficiency congenital adrenal hyperplasia. Pediatr. Clin. N. Am. 2011, 58, 1281-1300. [CrossRef]

9. Pang, S.Y. Worldwide experience in newborn screening for classical congenital adrenal hyperplasia due to 21-hydroxylase deficiency. Pediatrics 1988, 81, 866. [CrossRef]

10. Pang, S.; Hotchkiss, J.; Drash, A.L.; Levine, L.S.; New, M.I. Microfilter paper method for $17 \alpha$-hydroxyprogesterone radioimmunoassay: Its application for rapid screening for congenital adrenal hyperplasia. J. Clin. Endocrinol. Metab. 1977, 45, 1003-1008. [CrossRef]

11. Gong, L.-F.; Gao, X.; Yang, N.; Zhao, J.-Q.; Yang, H.-H.; Kong, Y.-Y. A pilot study on newborn screening for congenital adrenal hyperplasia in Beijing. J. Pediatr. Endocrinol. Metab. 2019, 32, 253-258. [CrossRef]

12. Heather, N.L.; Seneviratne, S.N.; Webster, D.; Derraik, J.G.B.; Jefferies, C.; Carll, J.; Jiang, Y.; Cutfield, W.S.; Hofman, P.L. Newborn screening for congenital adrenal hyperplasia in New Zealand, 1994-2013. J. Clin. Endocrinol. Metab. 2015, 100, 1002-1008. [CrossRef]

13. Kumar, R.K.; Das, H.; Kini, P. Newborn screening for congenital adrenal hyperplasia in India: What do we need to watch out for? J. Obstet. Gynecol. India 2016, 66, 415-419. [CrossRef] [PubMed]

14. Kopacek, C.; de Castro, S.M.; Prado, M.J.; da Silva, C.M.D.; Beltrão, L.A.; Spritzer, P.M. Neonatal screening for congenital adrenal hyperplasia in Southern Brazil: A population based study with 108,409 infants. BMC Pediatr. 2017, 17, 22. [CrossRef] [PubMed]

15. Pang, S.; Murphey, W.; Levine, L.S.; Spence, D.A.; Leon, A.; LaFranchi, S.; Surve, A.S.; New, M.I. A pilot newborn screening for congenital adrenal hyperplasia in Alaska. J. Clin. Endocrinol. Metab. 1982, 55, 413-420. [CrossRef] [PubMed]

16. Pearce, M.; DeMartino, L.; McMahon, R.; Hamel, R.; Maloney, B.; Stansfield, D.-M.; McGrath, E.C.; Occhionero, A.; Gearhart, A.; Caggana, M.; et al. Newborn screening for congenital adrenal hyperplasia in New York State. Mol. Genet. Metab. Rep. 2016, 7, 1-7. [CrossRef]

17. Perrin, C.W. Neonatal screening for congenital adrenal hyperplasia. Nat. Rev. Endocrinol. 2009, 5, 490.

18. Sarafoglou, K.; Gaviglio, A.; Hietala, A.; Frogner, G.; Banks, K.; McCann, M.; Thomas, W. Comparison of newborn screening protocols for congenital adrenal hyperplasia in preterm infants. J. Pediatr. 2014, 164, 1136-1140. [CrossRef]

19. Therrell, B.L.; Adams, J. Newborn screening in North America. J. Inherit. Metab. Dis. 2007, 30, 447-465. [CrossRef]

20. Tsuji-Hosokawa, A.; Konishi, K.; Hasegawa, S.; Anazawa, A.; Onishi, T.; Ono, M.; Morio, T.; Kitagawa, T.; Kashimada, K. Newborn screening for congenital adrenal hyperplasia in Tokyo, Japan from 1989 to 2013: A retrospective population-based study. BMC Pediatr. 2015, 15, 1-8. [CrossRef]

21. Van Der Kamp, H.J.; Noordam, C.; Elvers, B.; Van Baarle, M.; Otten, B.J.; Verkerk, P.H. Newborn screening for congenital adrenal hyperplasia in The Netherlands. Pediatrics 2001, 108, 1320-1324. [CrossRef]

22. Van der Linde, A.A.A.; Schönbeck, Y.; van der Kamp, H.J.; Akker, E.L.V.D.; van Albada, M.E.; Boelen, A.; Finken, M.J.J.; Hannema, S.E.; Hoorweg-Nijman, G.; Odink, R.J.; et al. Evaluation of the Dutch neonatal screening for congenital adrenal hyperplasia. Arch. Dis. Child. 2019, 104, 653-657. [CrossRef]

23. Pang, S.; Clark, A.; Neto, E.C.; Giugliani, R.; Dean, H.; Winter, J.; Dhondt, J.-L.; Farriaux, J.; Graters, A.; Cacciari, E.; et al. Congenital adrenal hyperplasia due to 21-hydroxylase deficiency: Newborn screening and its relationship to the diagnosis and treatment of the disorder. Screening 1993, 2, 105-139. [CrossRef]

24. Lacey, J.M.; Minutti, C.Z.; Magera, M.J.; Tauscher, A.L.; Casetta, B.; McCann, M.; Lymp, J.; Hahn, S.H.; Rinaldo, P.; Matern, D. Improved specificity of newborn screening for congenital adrenal hyperplasia by second-tier steroid profiling using tandem mass spectrometry. Clin. Chem. 2004, 50, 621-625. [CrossRef] [PubMed]

25. 12118_Newborn Bloodspot Framework_V4_WEB.PDF. Available online: http://www.cancerscreening. gov.au/internet/screening/publishing.nsf/Content/C79A7D94CB73C56CCA257CEE0000EF35/\$File/12118_ Newborn\%20Bloodspot\%20Framework_V4_WEB.PDF (accessed on 29 June 2020).

26. Wudy, S.; Schuler, G.; Guijo, A.S.; Hartmann, M. The art of measuring steroids: Principles and practice of current hormonal steroid analysis. J. Steroid Biochem. Mol. Boil. 2018, 179, 88-103. [CrossRef] [PubMed] 
27. Wilcken, B.; Wiley, V. Fifty years of newborn screening. J. Paediatr. Child Heal. 2015, 51, 103-107. [CrossRef]

28. Wilcken, B.; Wiley, V. Newborn screening. Pathology 2008, 40, 104-115. [CrossRef]

29. Gleeson, H.K.; Wiley, V.; Wilcken, B.; Elliott, E.J.; Cowell, C.; Thonsett, M.; Byrne, G.; Ambler, G. Two-year pilot study of newborn screening for congenital adrenal hyperlasia in New South Wales compared with nationwide case surveillance in Australia. J. Paediatr. Child Heal. 2008, 44, 554-559. [CrossRef] [PubMed]

30. Warne, G.L.; Armstrong, K.L.; Faunce, T.; Wilcken, B.M.; Boneh, A.; Geelhoed, E.; Craig, M.E. The case for newborn screening for congenital adrenal hyperplasia in Australia. Med. J. Aust. 2010, 192, 107. [CrossRef]

31. Rossi, C.; Calton, L.; Brown, H.A.; Gillingwater, S.; Wallace, A.M.; Petrucci, F.; Ciavardelli, D.; Urbani, A.; Sacchetta, P.; Morris, M.R. Confirmation of congenital adrenal hyperplasia by adrenal steroid profiling of filter paper dried blood samples using ultra-performance liquid chromatography-tandem mass spectrometry. Clin. Chem. Lab. Med. 2011, 49, 677-684. [CrossRef]

32. White, P.C. Optimizing newborn screening for congenital adrenal hyperplasia. J. Pediatr. 2013, 163, 10-12. [CrossRef]

33. Turcu, A.F.; Auchus, R.J. The next 150 years of congenital adrenal hyperplasia. J. Steroid Biochem. Mol. Boil. 2015, 153, 63-71. [CrossRef]

34. Hird, B.E.; Tetlow, L.; Tobi, S.; Patel, L.; Clayton, R. No evidence of an increase in early infant mortality from congenital adrenal hyperplasia in the absence of screening. Arch. Dis. Child. 2014, 99, 158-164. [CrossRef] [PubMed]

35. Van Vliet, G.; Czernichow, P. Screening for neonatal endocrinopathies: Rationale, methods and results. Semin. Neonatol. 2004, 9, 75-85. [CrossRef]

36. Speiser, P.W.; Azziz, R.; Baskin, L.S.; Ghizzoni, L.; Hensle, T.W.; Merke, D.P.; Meyer-Bahlburg, H.F.L.; Miller, W.L.; Montori, V.M.; Oberfield, S.E.; et al. Congenital adrenal hyperplasia due to steroid 21-hydroxylase deficiency: An Endocrine Society clinical practice guideline. J. Clin. Endocrinol. Metab. 2010, 95, 4133-4160. [CrossRef] [PubMed]

37. Hayashi, G.Y.; Carvalho, D.F.; De Miranda, M.C.; Faure, C.; Vallejos, C.; Brito, V.N.; Rodrigues, A.D.S.; Madureira, G.; Mendonca, B.B.; Bachega, T.A. Neonatal 17-hydroxyprogesterone levels adjusted according to age at sample collection and birthweight improve the efficacy of congenital adrenal hyperplasia newborn screening. Clin. Endocrinol. 2017, 86, 480-487. [CrossRef]

38. Chan, C.L.; McFann, K.; Taylor, L.; Wright, D.; Zeitler, P.; Barker, J. Congenital adrenal hyperplasia and the second newborn screen. J. Pediatr. 2013, 163, 109-113. [CrossRef]

39. Votava, F.; Novotna, D.; Kracmar, P.; Vinohradska, H.; Stahlova-Hrabincova, E.; Vrzalová, Z.; Neumann, D.; Malikova, J.; Lebl, J.; Matern, D. Lessons learned from 5 years of newborn screening for congenital adrenal hyperplasia in the Czech Republic: 17-hydroxyprogesterone, genotypes, and screening performance. Eur. J. Nucl. Med. Mol. Imaging 2012, 171,935-940. [CrossRef]

40. Dörr, H.G.; Odenwald, B.; Nennstiel-Ratzel, U. Early diagnosis of children with classic congenital adrenal hyperplasia due to 21-hydroxylase deficiency by newborn screening. Int. J. Neonatal Screen. 2015, 1, 36-44. [CrossRef]

41. Gidlöf, S.; Wedell, A.; Guthenberg, C.; von Döbeln, U.; Nordenström, A. nationwide neonatal screening for congenital adrenal hyperplasia in Sweden. JAMA Pediatr. 2014, 168, 567. [CrossRef]

42. Van der Kamp, H.J.; Oudshoorn, C.G.M.; Elvers, B.H.; Van Baarle, M.; Otten, B.J.; Wit, J.; Verkerk, P.H. Cutoff levels of 17- $\alpha$-hydroxyprogesterone in neonatal screening for congenital adrenal hyperplasia should be based on gestational age rather than on birth weight. J. Clin. Endocrinol. Metab. 2005, 90, 3904-3907. [CrossRef]

43. Congenital adrenal hyperplasia (CAH) condition assessment summary-March 2019.pdf. Available online: https://www.google.com.hk/url?sa=t\&rct=j\&q=\&esrc=s\&source=web\& $\mathrm{cd}=\& v e d=2$ ahUKEwiH7MSEzpTrAhUqyosBHbNVBCQQFjAAegQIAhAB\&url=http\%3A\% 2F\%2Fwww.cancerscreening.gov.au $\% 2$ Finternet $\% 2$ Fscreening $\% 2 F p u b l i s h i n g . n s f \% 2 F C o n t e n t \%$ 2FC79A7D94CB73C56CCA257CEE0000EF35\%2F\%24File\%2FCongenital\%2520adrenal \%2520hyperplasia\% 2520(CAH)\%2520condition\%2520assessment\%2520summary\%2520-\%2520March\%25202019.pdf\&usg= AOvVaw0lv0qPSTCr6j5LW7p2zRCQ (accessed on 29 June 2020).

44. Guran, T.; Tezel, B.; Gürbüz, F.; Eklioğlu, B.S.; Hatipoğlu, N.; Kara, C.; Şimşek, E.; Çizmecioğlu, F.M.; Ozon, A.; Baş, F.; et al. Neonatal screening for congenital adrenal hyperplasia in Turkey: A pilot study with 38,935 infants. J. Clin. Res. Pediatr. Endocrinol. 2019, 11, 13-23. [CrossRef] 
45. Choi, R.; Park, H.-D.; Oh, H.J.; Lee, K.; Song, J.; Lee, S. Dried blood spot multiplexed steroid profiling using liquid chromatography tandem mass spectrometry in Korean neonates. Ann. Lab. Med. 2019, 39, 263-270. [CrossRef] [PubMed]

46. Bialk, E.R.; Lasarev, M.R.; Held, P.K. Wisconsin's screening algorithm for the identification of newborns with congenital adrenal hyperplasia. Int. J. Neonatal Screen. 2019, 5, 33. [CrossRef]

47. Tieh, P.Y.; Yee, J.K.; Hicks, R.; Mao, C.S.-M.; Lee, W.-N. Utility of a precursor-to-product ratio in the evaluation of presumptive positives in newborn screening of congenital adrenal hyperplasia. J. Perinatol. 2017, 37, 283-287. [CrossRef] [PubMed]

48. Boelen, A.; Ruiter, A.F. Determination of a steroid profile in heel prick blood using LC-MSMS. Bioanalysis 2016, 8, 375-384. [CrossRef]

49. Janzen, N.; Peter, M.; Steuerwald, U.; Terhardt, M.; Holtkamp, U.; Sander, S. Newborn screening for congenital adrenal hyperplasia: Additional steroid profile using liquid chromatography-tandem mass spectrometry. J. Clin. Endocrinol. Metab. 2007, 92, 2581-2589. [CrossRef]

50. Hicks, R.A.; Yee, J.K.; Mao, C.S.; Graham, S.; Kharrazi, M.; Lorey, F.; Lee, W.P. Precursor-to-product ratios reflect biochemical phenotype in congenital adrenal hyperplasia. Metabolomics 2014, 10, 123-131. [CrossRef]

51. El-Maouche, D.; Arlt, W.; Merke, D.P. Congenital adrenal hyperplasia. Lancet 2017, 390, 2194-2210. [CrossRef]

52. Pignatelli, D.; Carvalho, B.L.; Palmeiro, A.; Barros, A.; Guerreiro, S.G.; Maçut, D. The complexities in genotyping of congenital adrenal hyperplasia: 21-hydroxylase deficiency. Front. Endocrinol. 2019, 10, 10. [CrossRef]

53. Sarafoglou, K.; Lorentz, C.P.; Otten, N.; Oetting, W.S.; Grebe, S.K.G. Molecular testing in congenital adrenal hyperplasia due to 21?-hydroxylase deficiency in the era of newborn screening. Clin. Genet. 2012, 82, 64-70. [CrossRef]

54. Turan, I.; Tastan, M.; Boga, D.D.; Gurbuz, F.; Kotan, L.D.; Tuli, A.; Yuksel, B. 21-Hydroxylase deficiency: Mutational spectrum and genotype-phenotype relations analyses by next-generation sequencing and multiplex ligation-dependent probe amplification. Eur. J. Med. Genet. 2019, 63, 103782. [CrossRef]

(C) 2020 by the authors. Licensee MDPI, Basel, Switzerland. This article is an open access article distributed under the terms and conditions of the Creative Commons Attribution (CC BY) license (http://creativecommons.org/licenses/by/4.0/). 